days to a week after the commencement of the medicine; in none did cardiac complications arise during the course of the treatment; and, I think, the convalescence was more rapid than in cases I have seen treated by the salicylate of soda.

In Case v, there was a slight relapse, probably owing to the medicine having been too early discontinued; for, on its being resumed, the pain and fever speedily subsided.

Benzoate of soda possesses this advantage, that it does not give rise to the nausea and depression, or the unpleasant head phenomena, which the salicylate frequently produces. It is most convenient to prescribe it in the form of a mixture, and it may be given in doses of fifteen or twenty grains every two or three hours. It should also be continued in diminished doses for twenty-four or forty-eight hours after the rheumatic symptoms have disappeared.

\section{DELIRIUM FOLLOWING THE TREATMENT OF ACUTE RHEUMATISM BY SALICYLIC ACID.}

\section{By T. D. ACLAND, M.B.Oxon.}

IN the BRITISH MEDICAL JouRNAL for January 29th, there are reports of six cases of acute rheumatism treated with salicylic acid and accom. panied by delirium. In his remarks on one of these cases, Dr. Bastian put before his hearers the most recent views which have been expressed as to the causation of the delirium; and gave, as his opinion, that Dr. Murchison was probably wrong in attributing the symptoms to uræmia. In the year 1877, through the kindness of Drs. Bristowe and Ord, the opportunity was given me of making some observations on this point, which incline me to believe that, when the delirium is the result of the treatment, and not a natural sequence of the disease, uræmia may play an active part in its causation.

The method in which the inquiry was conducted was as follows: The urine of patients who were being treated with salicylate of soda was collected for each successive period of twenty-four hours. The percentage of urea was estimated from a sample of the whole (the mean of three observations being, as a rule, taken); and then, by a simple calculation, the total amount of urea excreted in the day was determined. The result of these inquiries made in four cases-one of which lasted for twenty-one days - was to lead me to the following conclusions.

I. As a rule, the treatment was followed by a decline in the tem. perature.

2. The decline in the temperature was generally coincident with or followed by a marked diminution in the excretion of nitrogen, which, except in very minute quantities, is wholly excreted as urea (Dr. S. H. West, Proc. Roy. Soc., 188o)

3. The lowering of the temperature, diminution of pain, and lessened excretion of urea, were nearly coincident.

In two of the cases, these results were well marked; in the one, treatment was discontinued twice, with the result each time of increased pain, pyrexia, and total amount of urea excreted per diem; in the other, in which it was unfortunately impossible to obtain accurate observations, treatment was discontinued five times, with the result, on each occasion, of similar changes in the temperature and urea excretion. In both cases, as soon as the salicylic treatment was resumed, the pain was relieved, the temperature fell, and the amount of urea passed in the twenty-four hours was much lessened. Do the facts justify a supposition that, supposing the temperature had not fallen and the salicylic acid had still been continued, delirium would have re. sulted? Further researches alone can decide; and the difficulty of obtaining all the urine which is passed when a patient is unconscious is so great that as yet my efforts to do so have failed.

Five cases in which albuminuria has been present have come under my notice. In all of them it has passed away during the continuance of the salicylic treatment; though, in one case, there was a very considerable amount of albumen present when treatment was commenced. Should these statements be borne out by further inquiries, they may have an important bearing on the vexed question of the causation of delirium by salicylic acid; since, if they are true, there may possibly be uræmia due to lessened discharge, or perhaps lessened formation of soluble nitrogenous excreta, without the occurrence of nephritis; and it would seem probable that, in most cases, the albuminuria is only a part of the febrile process, and not due to the drug.

The results which have been observed in the treatment of enteric fever with salicylic acid seem to favour the above views; since the drug, in many recorded cases, has precipitated the appearance of the "typhoid" symptoms, which are generally ascribed to uræmia.

From the nature of the investigation, it has been difficult to obtain complete records of any large number of cases. Some accident has, in many of them, broken the chain of observations, and made them incomplete; but those which have been recorded (St. Thomas's Hospital Reports, 1878), may, I venture to hope, lead others interested in the subject to continue the inquiry.

\section{ACUTE PULMONARY TUBERCULOSIS}

By J. P. H. BOILEAU, M.D.,

Assistant Professor of Pathology, Army Medical School, Netley.

THE rarity with which this disease is followed by recovery is very clearly evidenced by the remarks of Dr. McCall Anderson, in the British Medical Journal of February 19th. I have treated two cases of this disease. In the first, all doubts as to diagnosis were cleared up by a post mortem examination; in the second, recovery took place, and it is now more than nine years since my patient was attacked. The following extract is from my case-book.

CASE 1.-A. B., aged 29 (service eleven years), consulted me at Barbadoes on July 20th, 1871 . He was suffering from pulmonary distress, cough, and hæmoptysis. He was placed on the sick-list; and I found that, although the cough had not been severe until very lately, he had been annoyed by it for several weeks past, and that it became aggravated after a hard ride into the country, which he took on the 14 th instant.

There appears to have been an hereditary tendency to phthisis in his family. In the autumn of 1865 , at Malta, I attended him for hæmoptysis, of which he had several attacks. He was not, however, then on the sick-list; and, during the six years that had since elapsed, he had enjoyed excellent health.

On examination, I found pulse (lying) 88; respiration 24; temperature (axillary) IOr. He complained of wandering pain and heaviness about the front of the chest, headache, dyspnoa, and constipation. I found the respiratory sounds very feeble throughout the lungs, a'general slight dulness, but no positive stethescopic sign of pleurisy, pneumonia, or bronchitis. In the evening, his temperature had risen to $103^{\circ}$; pulse 100; respirations 25.

Subsequent examinations gave the following results.

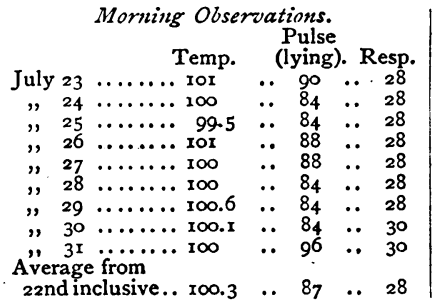

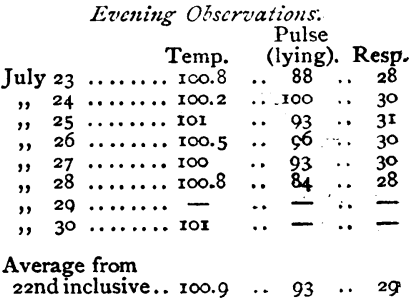

The sputa were scanty, and viscid, yellowish, and opalescent ; latterly presenting milky-white spots and bloody streaks; no rust or frost. The cough was, therefore, more or les; dry; it was often paroxysmal, and easily excited. The skin, which was delicate, emitted a peculiar odour ; it was always moist. He became subject to flushes of heat, which could be seen in his face. I noticed an obscure crepitus at the base of the right lung; this gradually increased in loudness and extent. Three days after my first examination, I found dry crepitation, anteriorly and superiorly in the same lung; this became exceedingly well marked towards the apex, with dulness; vocal resonance and fremitus being morbidly increased. He lost flesh daily, and gradually became weaker. There came to be a difference of 30 between his standing and his lying pulse. Having made up my mind that he was the subjéct of acute tuberculosis, I submitted his case to the principal medical officer of the station, and recommended that he should be sent away from the island as speedily as possible. He embarked for England on August Ioth, in a very unpromising state; but he gradually got better and stronger, he resumed his military duties, and he has done many hard day's work since. He is now again serving abroad. I beliêve that the sea-voyage home, taken during the onset of the disease, sayed his life; and I felt at the time that every hour he continued in the island was militating dreadfully against his recovery, so we got him out of the place with all possible speed.

WE understand that the Director-General of the Army Medical Department will not vacate his appointment on the expiration of his term of office in April next, and that he will continue to occupy his present position for another year. 